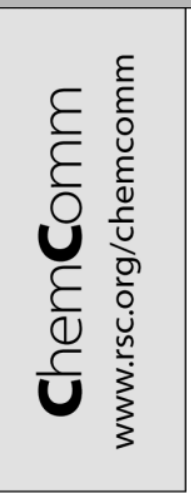

\title{
Zeolite coated ATR crystals for new applications in FTIR-ATR spectroscopy
}

\author{
Zheng Wang, ${ }^{a}$ Margareta L. Larsson, ${ }^{b}$ Mattias Grahn, ${ }^{a}$ Allan Holmgren*b and Jonas Hedlund ${ }^{* a}$ \\ a Division of Chemical Technology, Luleå University of Technology, S-971 87 Luleå, Sweden. \\ E-mail: jonas.hedlund@ltu.se; Fax: + 46920 491199; Tel: + 46920492105 \\ ${ }^{b}$ Division of Chemistry, Luleå University of Technology, S-971 87 Luleå, Sweden. \\ E-mail: allan.holmgren@ltu.se; Fax: + 46920 491199; Tel: + 46920492140
}

Received (in Cambridge, UK) 8th July 2004, Accepted 17th September 2004

First published as an Advance Article on the web 25th October 2004

Thin silicalite-1 films were grown on ATR crystals and used for detection of low amounts of organic molecules in a gas flow by FTIR spectroscopy.

Molecular sieves have a number of unique properties that make them interesting in various application areas. ${ }^{1,2}$ They are inorganic, microporous materials with large surface areas and well-defined channel systems due to the fact that they are crystalline. ${ }^{3}$ Molecular sieves are currently used in large quantities as shape-selective catalysts, adsorbents and ion-exchangers. Selective and strong adsorption render molecular sieves interesting in sensors for detection of low concentrations of molecules in gas or liquid phase. A limitation in novel as well as in several of the established applications of molecular sieves is the lack of knowledge of the adsorption and transport phenomena determining the performance of the materials. Despite the fact that the number of studies devoted to the adsorption of various molecules in zeolites is numerous, few investigations exist where competitive adsorption from mixtures has been studied. Moreover, the reports focusing on kinetic aspects of adsorption, particularly competitive adsorption, are few. This is obviously related to the fact that such studies require well-defined materials, but also to a lack of simple analytical techniques making such studies possible.

In the last decade total internal reflection (TIR) spectroscopy using optical fibers and ATR (Attenuated Total Reflection) elements has become one of the fastest growing sensor applications within modern analytical chemistry. ${ }^{46}$ In the ATR technique, the IR beam is totally reflected inside a waveguide. At each reflection an evanescent field is created at the surface of the waveguide. This field is used in ATR spectroscopy to probe the near vicinity of the waveguide. The ATR-technique is useful for investigation of interfacial phenomena in situ. Coated internal reflection elements (IRE) are especially interesting and have been used in various applications. ${ }^{7,8}$ A number of studies report the use of polymer coated IREs for detection of organic pollutants and in particular chlorinated hydrocarbons in water. ${ }^{9-11}$ It has been demonstrated that the thin film serves as an extractor phase enriching the analyte in close vicinity to the sensor surface. Such studies also suggest that the use of a solid film with high surface area, with maximum adsorbent/IRE contact, is vital. However, applications for various film/IRE combinations are really limited by the ability of depositing a thin, uniform, self-supporting film upon the IRE.

A method employing seeding has been developed in our laboratory for the synthesis of ultrathin as well as thick zeolite films. ${ }^{12}$ The method is very flexible, not very surface sensitive, and allows for reproducible preparation of films of desired thickness and crystal orientation using a number of zeolite-substrate combinations. ${ }^{13-15}$ The objective of the work described in the present communication is to synthesize and characterize thin silicalite- 1 films on ATR-crystals and to demonstrate the use of the film for detection of organic compounds in a gas flow. To the best of our knowledge, well defined molecular sieve films supported by ATR-crystals for FTIR spectroscopy have not been reported in the literature before.

A schematic of the flow cell (volume $\sim 3 \mathrm{ml}$ ) containing the silicalite-1 coated ATR crystal is shown in Fig. 1. The size of the $\mathrm{Si}$

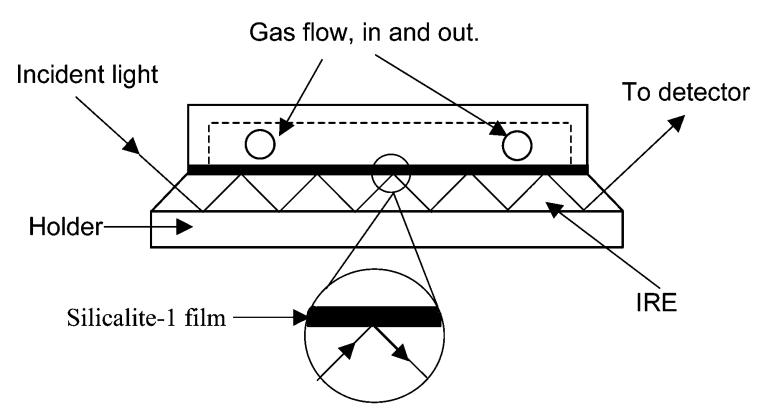

Fig. 1 Schematic picture of the flow cell and IRE.

IRE is $50 \times 20 \times 1 \mathrm{~mm}^{3}$ with a trapezoidal form $\left(45^{\circ}\right)$. Only one side of the ATR element is coated with a silicalite-1 film. The flow cell is constructed of stainless steel and is sealed with a viton o-ring. The IRE in the cell was placed in the beam path in the spectrometer and a gas flow was fed to the cell via tubing through the lid of the spectrometer. The gas flows used in the experiment were produced by a gas delivery system consisting of three mass flow controllers and two saturators containing hydrocarbons.

The Si ATR crystal was first modified by the following procedure: The cutting edges and the back side were coated with an epoxy polymer (Araldite 2014, Vantico AG, Basel, Switzerland) and then moved into a preheated oven at $50{ }^{\circ} \mathrm{C}$ for $24 \mathrm{~h}$ in order to complete the curing of the polymer. The polymer protects the edges and back side of the IRE from zeolite crystallization. The polymer protected Si IRE was rinsed for 10 minutes in acetone in an ultrasonic bath and then boiled for 5 minutes in a mixture having the volume composition of $5 \mathrm{H}_{2} \mathrm{O}: 1 \mathrm{H}_{2} \mathrm{O}_{2}: 1 \mathrm{NH}_{3}\left(30 \mathrm{wt} \% \mathrm{H}_{2} \mathrm{O}_{2}\right.$ and $25 \mathrm{wt} \% \mathrm{NH}_{3}$ ). The crystal was rinsed with distilled water and boiled for 5 minutes in another mixture with a volume composition of $6 \mathrm{H}_{2} \mathrm{O}: 1 \mathrm{H}_{2} \mathrm{O}_{2}: 1 \mathrm{HCl}\left(30 \mathrm{wt} \% \mathrm{H}_{2} \mathrm{O}_{2}\right.$ and $\left.37 \mathrm{wt} \% \mathrm{HCl}\right)$. Finally, the substrate was rinsed thoroughly with distilled water.

A short description of the synthesis of zeolite films follows; details can be found elsewhere. ${ }^{15}$ The silica source used was tetraetoxysilane (TEOS, >98\%, Merck). Tetrepropylammonium hydroxide (TPAOH, $40 \%$ aqueous solution, Sigma) was used as the structure directing agent and the alkali source. Distilled water was used in all cases. The method used for film preparation in the present study basically consists of three main steps: i) Preparation of $60 \mathrm{~nm}$ colloidal molecular sieve seeds. The seeds are grown from a synthesis mixture with a molar composition of $9 \mathrm{TPAOH}: 25 \mathrm{SiO}_{2}$ : $360 \mathrm{H}_{2} \mathrm{O}: 100 \mathrm{EtOH}$. ii) Deposition of seeds onto cationic polymer (Redifloc 4150, Eka Chemicals) coated substrate by electrostatic adsorption. iii) Growth of the seed crystals into a continuous, polycrystalline film at $100{ }^{\circ} \mathrm{C}$ for $24 \mathrm{~h}$ in a synthesis solution with the molar composition $3 \mathrm{TPAOH}: 25 \mathrm{SiO}_{2}: 1450 \mathrm{H}_{2} \mathrm{O}$ : $100 \mathrm{EtOH}$. After completed film crystallization, the samples are rinsed overnight with a $0.1 \mathrm{M}$ ammonia solution and dried at room temperature. Finally, in order to remove the TPA template molecules blocking the zeolite channels and to remove the polymer protecting the cutting edges and back side, all films were heated in 

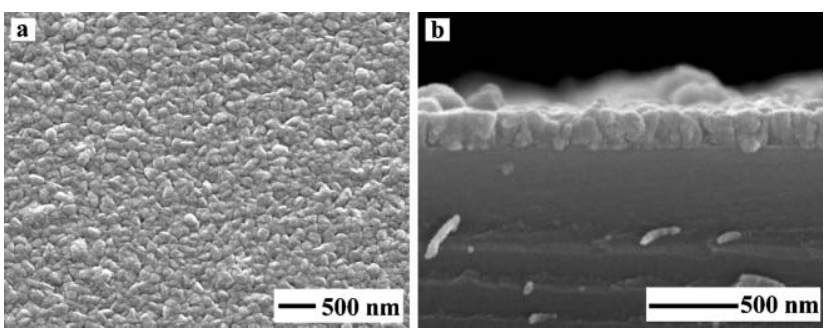

Fig. 2 Top (a) and side (b) view images of a silicalite-1 film on a Si IRE.

air at $500{ }^{\circ} \mathrm{C}$ for $4 \mathrm{~h}$ using a heating and cooling rate of $0.8^{\circ} \mathrm{C}$ per minute.

A Philips XL 30 Scanning Electron Microscope (SEM) equipped with $\mathrm{a} \mathrm{LaB}_{6}$ emission source was used for studies of surface morphology and film thickness. A Siemens D5000 powder X-ray diffractometer (XRD) running in the Bragg-Brentano geometry was used to collect XRD data. The IR-spectrometer used was a Bruker IFS113V (pressure $\sim 1 \mathrm{~mm} \mathrm{Hg}$ ) equipped with a MCTdetector.

After $24 \mathrm{~h}$ crystallization at $100{ }^{\circ} \mathrm{C}$, the adsorbed seed crystals had increased in size and formed a continuous and transparent film, see Fig. 2. A top view of the calcined silicalite-1 film on a Si crystal is shown in (a). The calcined film is dense and continuous. No cracks or other defects can be detected by SEM. Fig. 2 (b) shows a side view image of the film. The film thickness is constant and about $180 \mathrm{~nm}$. XRD patterns were collected in the $2 \theta$ region from $5^{\circ}$ to $27^{\circ}$ where the most intense MFI reflections are located. The XRD data confirms that the films consist of pure MFI crystals.

In Fig. 3 the spectrum of a silicalite-1 film on a Si ATR element is shown (A). Silicalite-1 has some spectral features from 1600 $2000 \mathrm{~cm}^{-1}$; these are assigned to the overtones of silicalite- 1 lattice vibrations. The spectrum also shows an IR band in the $\mathrm{OH}_{-}$ stretching region at $3743 \mathrm{~cm}^{-1}$ corresponding to terminal SiOHgroups. Before the spectrum of the film was recorded, the silicalite- 1 coated Si IRE had been dried at $250{ }^{\circ} \mathrm{C}$ for more than $12 \mathrm{~h}$ in dry argon. Spectrum B was recorded 5 minutes after the cell had been connected to a flow of helium and $n$-hexane $\left(p / p_{0} \approx 0.01\right)$. For both spectrum $\mathrm{A}$ and $\mathrm{B}$, a single beam spectrum of a dry uncoated $\mathrm{Si}$ IRE was used as background. In spectrum $\mathrm{C}$, the background was the silicalite- 1 coated IRE. The peak-height at $2960 \mathrm{~cm}^{-1}$ in spectrum $\mathrm{C}$ was about 0.1 absorbance units. This is a promising result since it should be possible to detect at least 100 times less than this amount and still achieve a good signal to noise ratio. It was not possible to detect n-hexane when the experiment was carried out with a Si IRE that was not coated with a silicalite-1 film.

In summary, this communication presents the synthesis and characterization of a thin silicalite-1 film on a Si IRE substrate. It was possible to detect low concentrations of organic molecules in a gas flow by this sensor in combination with FTIR spectroscopy. The sensor offers the possibility to study both the adsorbate and the adsorbent. Another intriguing possibility that should be

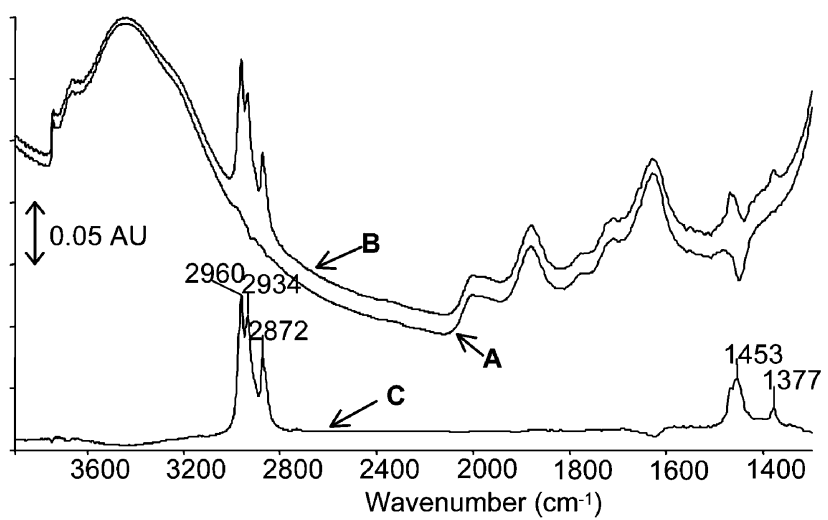

Fig. 3 (A) Spectrum of a silicalite-1 film on a silicon ATR-element, (B) spectrum of silicalite-1 film 5 minutes after the cell was filled with a dilute gas mixture of $\mathrm{n}$-hexane in helium $\left(p / p_{0} \approx 0.01\right)$, (C) spectrum of the $\mathrm{n}$-hexane adsorbed in the silicalite- 1 film on the silicon ATR-element. For both spectrum (A) and (B), the single beam spectrum of a Si IRE was used as background. In spectrum (C), the silicalite-1 coated Si IRE was used as background. The experiment was carried out at room temperature and atmospheric pressure.

mentioned is that of using ATR-FTIR for in situ studies of catalytic reactions taking place within the molecular sieve structure.

The Swedish Research Council (VR) is acknowledged for financial support of this work.

\section{Notes and references}

1 M. E. Davis, Nature, 2002, 417, 813.

2 M. Tsapatsis, AICHE J., 2002, 48, 654

3 D. W. Breck, Zeolite Molecular Sieves, Krieger Publ. Company, Malabar, 1984, p 5

4 K. K. Chittur, Biomaterials, 1998, 19, 357.

5 D. R. Scheuing, ACS Symp. Ser., 1991, 447, 1.

6 J. J. Workman, Appl. Spectrosc. Rev., 1999, 34, 1.

7 R. P. Sperline and Y. Song, Langmuir, 1997, 13, 6985.

8 T. Snabe and S. B. Petersen, J. Biotechnol., 2002, 95, 145.

9 R. Krska, K. Taga and R. Kellner, Appl. Spectrosc., 1993, 47, 1484.

10 R. Göbel, R. Krska, R. Kellner, R. W. Seitz and S. A. Tomellini, Appl. Spectrosc., 1994, 48, 678.

11 R. Göbel, R. W. Seitz, S. A. Tomellini, R. Krska and R. Kellner, Vib. Spectrosc., 1995, 8, 141.

12 J. Sterte, J. Hedlund and B. J. Schoeman, Procedure for preparing molecular sieve films, US Pat. 6,177,373, 2001.

13 J. Sterte, J. Hedlund, D. Creaser, O. Öhrman, Z. Wang, M. Lassinantti, Q. Li and F. Jareman, Catal. Today, 2001, 69, 323.

14 Z. Wang, J. Hedlund and J. Sterte, Microporous Mesoporous Mater., 2002, 52, 191

15 J. Hedlund, S. Mintova and J. Sterte, Microporous Mesoporous Mater., 1999, 28, 185 